\title{
The Practical Exploration of Calligraphy Education in Quality Education
}

\author{
Fan-lei MENG \\ Linyi University, Feixian Campus, Feixian, Shandong, China \\ Email:lydxmfl@126.com
}

Keywords: Quality education, Calligraphy education, Practical exploration.

\begin{abstract}
Being the soul and culture capital of our nation, calligraphy will help to promote the comprehensive development of teenagers in morality, intelligence, aesthetic judgement and fitness. The aim of calligraphy education identifies with the requirements of quality education, also, its wide basis of the masses and convenience in carrying out makes it the quality education suited to national conditions of China. Based on teaching practices, here I come up with the educational concept of "cultivating personality through calligraphy", and sum up the procedure teaching method of calligraphy---firstly training eyes, then training hands, then learning to hold writing brush, then practicing Chinese characters, then disciplining the mind, and at last cultivating the personality, hope to provide reference for front-line teaching.
\end{abstract}

\section{Introduction}

Chinese calligraphy is going onto the world stage and come to influence the world, it becomes the element and feature unique to China. Calligraphy education has subtle effect on students' comprehensive quality---namely morality, intelligence, aesthetic judgement and fitness, the cultivating function of calligraphy education on students is comprehensive as well as harmonious, it carries out aesthetic education through delicate artworks, and acclimate and affect people's soul and senses through beauty, enhance creativity, then recover and develop the sensibility lost because of unilateral education, help individuals gain psychological harmony and equilibrium, and affect intellectual development and character morality of them ind irectly.

\section{Calligraphy is soul and culture capital of Chinese nation}

Being an important component of Chinese traditional culture art, Chinese calligraphy art is the soul and culture capital of our nation. It has long history, rich connotations, complex skills of expression and diverse forms, all of these are spoken highly of by those nations and countries in the world that are familiar with or love Chinese culture. All adown the centuries, charismatic Chinese calligraphy shows the inner world of aesthetic personality of Chinese nation, demonstrates freedom spirit---the most dynamic and smart part of Chinese art, and different from rigid Confucianism, strict Legalism and otherworldly Daoism, it is the very art that carries most of oriental characteristics among Chinese arts, and demonstrates the authentic spiritual trace of Chinese nations through the writing. "Chinese calligraphy stands for the most important core of Chinese culture, namely the core of core"[1]. To learn Chinese culture well, it is rather necessary to climb the mountain named calligraphy. "It is impossible for people to learn the essential spirit of Chinese art while neglecting Chinese calligraphy" [2] . 
In the era of information and globalization, Chinese calligraphy has spread around the world, and will finally be well received around the world through people's cultivation. There are three western countries, namely France, Germany and United States, are closely related with China in calligraphy. Since 1950s, the influence of Chinese calligraphy on western arts is embodied mainly in the works of Abstract Expressionism. Through these works, we can see that western has absorbed brush strokes into their art traditions, many European artists get aspirations from Chinese calligraphy. "Modern Chinese Calligraphy Art Exhibition", which is held at Paris in 1998, has gained great success. It has been extended for another two months by the demand of audience after one-month exhibition, and the audience has reached 70000 approximately.

\section{Transform Ideas in Skills Training and Quality Education}

Firstly, let's talk about problems of preschoolers in practices of writing. For them, writing is also a kind of skills. It is a general rule that the writing should be correct, clear and neat, while "rule" generates "no rules, no standards" teaching view. Therefore, although writing education is relatively dull and boring, while children are hard-wired to move and prefer visual images, it appears that the writing education runs contrary to children's nature, however, this is necessary for children to receive education and integrate into society. The problem lies in educators, the problem they must think about and solve, is, how to accommodate calligraphy (writing)learning to children's nature, how to attract children with their own interest while not the pressure from parents, how to motivate children with the charm of calligraphy itself while not the sense of honor they get in calligraphy competitions? This is a great challenge we have no choice but meet in teaching. In other words, it is imperative for us to make teaching process entertaining and witty.

Secondly, the problems existing in the secondary calligraphy education, which is set up to play the role of quality education and aesthetics education.

As aesthetic education, the secondary calligraphy education come into being only because of the interest, it is relatively arbitrary and free, and should accomplish the shift from utility to artistic aesthetics. For students, learning calligraphy is not only to learn how to write well, but also to learn about art, to learn how to treat the beauty in art and in life. However, the reality is that, most of junior schools, high schools and secondary specialized schools do not open calligraphy class, while the left minority that can keep the calligraphy class still lack new positions and ideas in teaching contents and methods, instead of starting from enhancing students' interest, promoting their appreciation and then letting themselves choose the way to learn calligraphy, they just do it simply and rudely. For every teacher who involved in calligraphy education, whether calligraphy education should be positioned as "creative education" and "happy education", and reduce the enforceability and mandatory of handwriting education in elementary schools, and try best to inspire students' interest, make them regard calligraphy as a place to meet their creative desires and aesthetic ideals, all above would be the challenge we have to meet in handwriting education in elementary schools, which is featured as a combination of skills training and quality education.

\section{My Practice: Educational Concept of "cultivating personality through calligraphy" and Procedure Teaching Method of Calligraphy}

I have been engaged in calligraphy teaching for over ten years, with the establishment and consolidation of the discipline position of calligraphy, with the gradual 
completeness and advance of domestic calligraphy education systems, I explore actively in my teaching practices as well, then my unique educational concept of "cultivating personality through calligraphy", along with the procedure teaching method of calligraphy---firstly training eyes, then training hands, then learning to hold writing brush, then practicing Chinese characters, then disciplining the mind, and at last cultivating personality--- come into being.

\section{The Educational Concept of "cultivating personality through calligraphy"}

The emergence of an idea originates in practice rather than theory. The overall functions of calligraphy education in cultivating personality has been analyzed intensively and carefully earlier in the article. My initial perceptual knowledge of calligraphy education derived from my teaching experiences and performance of students. According to my observations, students with poor school performance also perform badly in calligraphy, their learning habits and attitudes are not very good as well; while students perform well in calligraphy will also get good grades in school, even some students' foundation of calligraphy is not good, but those who can study hard and keep practicing will make great progress in handwriting and in school performance.

The above situations are natural and rational. "Writing correct, clear and neat Chinese characters is the basic guarantee of effective written communication, is the basis of studying Chinese and other courses and further forming the ability of lifelong learning[3]. "Good handwriting naturally takes advantage at the beginning of study. Different from the abstract thinking activity in general cultural knowledge learning, handwriting practice is operative, it requires not only thinking but also practices, it needs the full participation of eyes, hands, body, brain and mind, all of this rarely happens in cultural studies. Different from common artistic disciplines and skills training activities, being closely related to Chinese characters and literature, calligraphy raise incomparable demand for learners in mind, sentiments and literary attainment. It is common acknowledged that "The handwriting is the expressions of personality" (Yang Xiong), "the style is the man", "handwritings is a kind of symbol. It symbolize the learning, the talent and the aspiration of people. In a word, the style is the man [4]." Li Ruiqing, an calligrapher in Republic period demonstrated calligraphy much more clearly: "Extensive reading is rather necessary for calligraphy learning, only with extensive literary attainment can people generate knowledge works. So since ancient times, although many great scholars are not very good at calligraphy, their works still have an air of cultivated refinement, people can feel the scholarliness from their works. Therefore, the individuality of calligraphy is the first important thing, otherwise the calligraphy is just common skill which is unworthy of attention[5]." Since ancient times, great calligraphers are mostly tremendous characters, and are well cultured in literature, they are famous in the world for their literary works, loyalty, achievement and moral integrity. Contrary to it, nowdays, the calligraphy community is definitely a mess, good mixed with evil, some people just neglect promoting comprehensive quality of themselves, they tend to regard calligraphy more a skill to earn their living than art, all above problems resulted from their deviation from the right path of calligraphy. 
The Procedure Teaching Method of Calligraphy---firstly training eyes, then training hands, then learning to hold writing brush, then practicing Chinese characters, then disciplining the mind, and at last cultivating the personality

Based on educational concept of "cultivating personality through calligraphy", I sum up the procedure teaching method of calligraphy---first eyes, then hands, then writing brush, then Chinese characters, then discipline the mind, and at last the personality.

Training Eyes: cultivating observation and aesthetic insight. Through reading copybooks. we can train observation and promote aesthetic insight, both of which are the main components of "eyes". As the name suggests, the copybook is used before the copy, learners observe the stipulated characters in the copybook, learn every single stroke, and the connections between strokes carefully, try they their best to learn the features of the stipulated characters by heart.

Observation is a kind of fine discernment on calligraphy forms, especially on abstract forms. The main way of learning calligraphy is practicing writing characters from copybooks, "precision is the most important part in observing characters, similarity is the most important part in coping characters "[6], it is an essential ability to grasp the shapes and stroke relations correctly and further to learn them by heart.

Aesthetic insight. Calligraphy creations values not only unique skills and rich connotations, but also elegant styles and artistic conceptions. "When learning calligraphy, ancient people are not simply imitating copybooks, sometimes they just open the books they'd like to copy, and observe it carefully, after all above, they start writing at their own will[7]." The first important thing to do in learning calligraphy is not writing practices, but appreciating calligraphy masterpieces, which will not only help to train observations of learners, motivate their inspirations, but also help to build up their correct aesthetic insight.

Training Hands: the stability and accuracy training of hands. It seems that writing needs only the direct participation of hands, but it also needs coordination and cooperation of hands, eyes and other body parts. So calligraphy practice has always emphasized correct regulations on writing postures and on ways to hold writing brush. The training goal of hands is "swift, stable and resolute".

Learning to hold Writing Brush: the ability to hold writing brush correctly. Calligraphy learning seems simple, while actually is a little more difficult. The difficulty lies mainly in its sophisticated techniques of writing. There are a couple of irreconcilable contradictions between rich technique of writing and purity requirements of calligraphic lines. In teaching activities, I usually teach the changes in lifting and pressing writing brush after students the "hands" procedure, and teach ways to start first stroke, to finish the last stroke and to write well, then teach them to practice writing with the tip of writing brush in the middle of stroke and is perpendicular to the paper, and when doing this, the elbow should be hanging in the air. In this way students can achieve the unity of knowled ge and practice.

Practicing Chinese Characters: the cultivating of logic thinking ability and creative power. Method is rather important in calligraphy writing, the procedure of imitating copybooks is actually a process of seeking the methods of writing through the form of stipulated characters. It is divided into two aspects: the stroke and the structure. The calligraphy values savvy, the competence of savvy equals to the logic ability and creative ability. "Similarity is the most important part in coping characters" is not the final goal, we imitate the copybooks, we study the traditional culture, while all these are for the sake of innovation. So, calligraphers should bear in mind the "commonness" and "individuality", those who want to make great achievements in calligraphy should equip themselves with deep traditional attainments, excellent 
aesthetic ideals and peculiar artistic personality, and grasp in macroscopic perspective, and start with micro aspects, only in this way can they make innovations of their own without always following the footsteps of ancients.

Disciplining the Mind: comprehensive requirements of will, sentiment and knowledge training. Calligraphy learning is more than physical skills practice, it requires not only the active participations of cognitive activity, but also good non-intelligence factors of learners, like perseverance, persistence, profound morality and rectitude. Calligraphy learning is a thing to resist loneliness, haste makes waste. It is best medicine to the impetuous social psychology. Calligraphy learners are required to master specialized knowledge as well as to profound cultural attainments. "Those who are not generalist with great ambitions cannot master the essence of calligraphy [8]." Huang Tingjian once make such comments on calligraphy works of Su Shi:"The profound cultural attainments of $\mathrm{Su} \mathrm{Shi}$ embodies on his calligraphy works, this is where others fall far behind him." [8] This gets to the point.

Cultivating the Personality: the enhancement of comprehensive quality. The calligraphy education isn't asking every student to be pro fessional calligrapher, but it's necessary and feasible to explore educational resources deeply, and promote students' comprehensive quality and mental state.

After many years of practical experiences in the forefront of teaching, the procedure teaching method of "cultivating personality through calligraphy" are proved to be quite effective and successful. Although it focus mainly on calligraphy writing, which is different from the pen writing in writing material, but there are more commonness on teaching methods and training skills between pen writing and calligraphy writing, so the procedure teaching method has universal values and significance to be popularized.

\section{Conclusions}

Chinese calligraphy is the soul and culture capital of our nation. Calligraphy education will help to promote the comprehensive development of teenagers in morality, intelligence, aesthetic judgment and fitness. The aim of calligraphy education identifies with the requirements of quality education, also, its wide basis of the masses and convenience in carrying out makes it the quality education suited to national conditions of China. The calligraphy education in elementary schools should be strengthened imperatively, and its position of being an independent discipline should be recovered. Compared with splendid calligraphic achievements of thousands of years, at the very beginning of calligraphy education, as calligraphic educators, we shoulder heavy responsibilities and has a long way to go. Only through carrying forward the calligraphy education can we prove ourselves worthy of the inheritance from the ancient and not let our descendents down.

\section{Acknowledgme nt}

The author wishes to express his sincere thanks to the editor and the anonymous referees for their valuable suggestions and helpful comments which could improve the presentation of the paper.

\section{Reference}

[1] Xiong Bingming, The Theory System of Chinese Calligraphy [M]. Chengdu: Sichuan Fine Arts Publishing House, 1990: p.167. 
[2] Chen Zhenlian, The Calligraphy Aesthetics [M]. Xi'an: Shanxi People's Fine Arts Publishing House, 1993: p.3.

[3] Ministry of Education of the People's Republic of China, Several Opinions on Promoting Calligraphy Education on Primary and Middle Schools [Z], 2002, (8).

[4] Liu Xizai(1990) Six Books of Liu Xizai on Arts [M].(xu zhongyu trans.) Chengdu: Bashu Press.

[5] Li Ruiqing, The Comments on Calligraphy in Jade-plum Temple[A]. Cui Erping, Calligraphy Treatises of Ming\&Qing Dynasty [C]. Shanghai: Shanghai Book\&Painting Press, 1994: p.1094.

[6] Sun Guoting, The Genealogy of Calligraphy[A]. Xiao Yuan, The Calligraphic Theory on Early Dang Dynasty [C].Changsha: Hunan Fine Arts Publishing House, 1997: p.140.

[7] Huang Tingjian, On Calligraphy[A].Liu Xiaoqing, Comments on Calligraphic Skills of China[C]. Shanghai: Shanghai Book\&Painting Press, 1991: p.454.

[8] Wang Xizhi, The Calligraphy Theory [A]. Liu Xiaoqing, Comments on Calligraphic Skills of China[C]. Shanghai: Shanghai Book \& Painting Press, 1991: p.321. 